\title{
TREATMENT OF GESTATIONAL DIABETES MELLITUS: INSULIN OR METFORMIN?
}

\author{
Prashant Subhash Somani1, Pranab Kumar Sahana ${ }^{2}$, Picklu Chaudhuri ${ }^{3}$, Nilanjan Sengupta ${ }^{4}$
}

1 Postdoctoral Trainee, Department of Endocrinology, NRS Medical College, Kolkata.

${ }^{2}$ Associate Professor, Department of Endocrinology, NRS Medical College, Kolkata.

${ }^{3}$ Associate Professor, Department of Obstetrics and Gynaecology, NRS Medical College, Kolkata.

4 Professor and HOD, Department of Endocrinology, NRS Medical College, Kolkata.

\begin{tabular}{l} 
ABSTRACT \\
\hline BACKGROUND \\
Metformin has established as an ideal first-line treatment for type 2 diabetes and hypothetically a particularly attractive drug for \\
use in pregnancy. Metformin is known to cross the placenta and its use in pregnancy has been limited by concerns regarding potential \\
adverse effects on both the mother and the foetus. Randomised trials to assess the efficacy and safety of its use for Gestational \\
Diabetes Mellitus (GDM) are lacking.
\end{tabular}

\section{METHODS}

Seventy six women with singleton pregnancy and diagnosed with GDM as per International Association of Diabetes and Pregnancy Study Groups (IADPSG) criteria were enrolled in study at 24 to 33 weeks of gestation. Subjects were randomly allocated to the intervention group $(n=38)$ and active control group $(n=38)$. Each subject in both groups received counseling on diet modification and physical activity, but failed to achieve glycaemic targets. Intervention group received metformin (with supplemental insulin if required). Active control group received human insulin (Regular, Neutral Protamine Hagedorn (NPH), or both). Primary outcome was neonatal birth weight. Secondary outcomes included maternal and neonatal complications with treatment satisfaction for allotted modality.

\section{RESULTS}

A total of 32 on metformin (Intervention group) and 33 on insulin (Active control group) subjects completed study. Of the 32 women assigned to metformin, $96.87 \%$ continued to receive metformin until delivery and $25 \%$ of the metformin group received supplemental insulin. There was no significant difference in mean birth weight between groups. There were no significant differences in neonatal and maternal complications between groups. However, treatment satisfaction (70.97\%) was significantly better in metformin group whereas better control of postprandial plasma glucose was achieved in insulin group.

\section{CONCLUSIONS}

Metformin is an effective, safe, cheap, and convenient alternative to insulin in the treatment of GDM patients. However, to determine the predictors of the need for supplemental insulin in women treated with metformin, will require further study.

\section{KEYWORDS}

GDM, Metformin, Insulin, Birth weight, Treatment Satisfaction

HOW TO CITE THIS ARTICLE: Somani PS, Sahana PK, Chaudhuri P, et al. Treatment of gestational diabetes mellitus: insulin or metformin?. J. Evolution Med. Dent. Sci. 2016;5(63):4423-4429, DOI: 10.14260/jemds/2016/1011

\section{INTRODUCTION}

Gestational Diabetes Mellitus (GDM) is a commonly encountered complication in pregnancy and is a heterogeneous disorder resulting from an interaction between environmental and genetic risk factors.(1) GDM is defined as "any degree of glucose intolerance with onset or first recognition during pregnancy." (2,3) Diabetes during pregnancy whether symptomatic or not is associated with significant risk of adverse perinatal outcome.(4) The prevalence of obesity and overweight is increasing worldwide.(5) The prevalence of GDM is increasing as the occurrence of obesity, one of the risk factors predisposing to impaired glucose tolerance is

Financial or Other, Competing Interest: None.

Submission 28-06-2016, Peer Review 21-07-2016,

Acceptance 29-07-2016, Published 05-08-2016.

Corresponding Author:

Dr. Prashant Subhash Somani,

Department of Endocrinology,

Nil Ratan Sircar Medical College and Hospital,

138, Acharya Jagadish Chandra Bose Rd,

Sealdah, Kolkata-700014,

West Bengal.

E-mail:drpssomani@gmail.com

DOI: $10.14260 /$ jemds/2016/1011 increasing. Regardless of criteria used for the diagnosis, the incidence of GDM is increasing, which affects $2-18 \%$ of all pregnancies worldwide. ${ }^{(6-8)}$ The detection of GDM during pregnancy provides an opportunity to identify women at risk of short-term and long-term complications. Some argue that pregnancy related hyperglycaemia might be completely physiological to provide nutrient to the foetus and whether there is a need to diagnose and treat GDM. It has been shown by Crowther et al and others that diagnosis and subsequent treatment are beneficial.(9-11) The aim of treatment is to maintain maternal blood glucose concentration within an acceptable range in a normal pregnancy. Interventions include lifestyle modification, Oral Hypoglycaemic Agents (OHAs), and insulin.

It is estimated that $70-90 \%$ of women diagnosed with GDM could achieve targeted glycaemic goals with lifestyle modification and nutrition therapy alone, $(12,13)$ but rest of the women often require additional treatment, which has conventionally been insulin.(14) The disadvantages of insulin for the mother include the need to give injections, risks of hypoglycaemia, and increase in appetite and weight.(15) Women maybe anxious about being on insulin and treatment 
compliance is an issue. It would be useful if there were alternative treatment options to insulin, preferably oral agents. Metformin, an oral biguanide, maybe a logical alternative to insulin for women with GDM who are unable to cope with the increasing insulin resistance of pregnancy. Metformin works primarily by decreasing hepatic glucose output, improving peripheral glucose uptake, and decreasing free fatty acid levels thus reducing insulin resistance.(16,17) Outside pregnancy, metformin is as efficacious as insulin or a sulfonylurea in achieving glycaemic control in people with newly diagnosed type 2 diabetes and it is not associated with weight gain.(15) Metformin crosses the placenta;(18-20) however, there is no evidence of adverse foetal effect and it is a class B drug in pregnancy.(21)

There are data from over 35 years ago reporting use of metformin in women with GDM or type 2 diabetes in pregnancy in South Africa. Published cohort studies showed similar perinatal mortality and morbidity for women treated with metformin compared with insulin.(22-24) Additional data regarding use of metformin in pregnancy comes from studies of women with polycystic ovarian syndrome, also associated with insulin resistance. Metformin has been shown to increase ovulation rates and fertility(25-27) and continuing it through pregnancy may reduce risks of miscarriage $(28,29)$ and GDM. Rates of preeclampsia and perinatal loss were not increased in women taking metformin compared with the community delivery population.(30) The lack of prospective randomised data, however, creates uncertainty about the use of metformin in women with diabetes in pregnancy. In Kolkata, we carried out a prospective randomised single centre open label trial comparing metformin with insulin treatment in women with GDM. The aim of the trial is to test the hypothesis that in women with GDM. Metformin treatment compared with insulin will result in similar perinatal outcomes and be associated with improved treatment-related satisfaction.

\section{METHODS}

\section{Ethics and Trial Design}

The trial was a randomised 1:1 parallel group open labelled single centre active controlled study with an intervention period from randomisation (24 to 33 weeks of gestation) to delivery. Institutional ethics committee approved study protocol. The trial was registered in ctri.nic.in, CTRI/2014/08/004835. The study was conducted between February 2014 and July 2015.

The study design included a screening visit (24 to 32 weeks of gestation), a randomisation visit, and subsequently patients treated with metformin or insulin had several appointments with a diabetologist and an obstetrician as necessary.

\section{Participants}

Subjects were recruited from outpatient departments. Eligible participants for the study were women aged $\geq 18$ and $\leq 35$ years with singleton pregnancy at 24 to 34 weeks of gestation. Those who were thought to meet eligibility criteria were invited to a screening visit. Written informed consent was obtained from all participants at the randomisation visit. All the participants were counseled about diet modifications and exercises and were instructed to maintain habits during study period.
Inclusion criteria were at least one abnormal plasma glucose value at screening OGTT as per IADPSG criteria who failed to achieve glycaemic targets with trial of diet modifications and exercises for 1 week.

\section{Exclusion Criteria included the following}

1. Diagnosis of diabetes before 24 weeks of pregnancy.

2. Pre-pregnancy diagnosis of diabetes.

3. $\mathrm{HbA} 1 \mathrm{c}>7.0 \%$.

4. Renal, hepatic, or cardiac failure.

5. Diabetic ketoacidosis.

6. Pregnancy with multiple foetuses.

7. Fetal growth restriction.

8. Ruptured membranes.

9. A fetal anomaly.

10. Bad obstetric history.

11. Preeclampsia and eclampsia.

12. Chronic hypertension.

13. Other major comorbid illness.

14. Placental abnormalities or low lying placenta.

15. Oligohydramnios or polyhydramnios.

16. Gestational hypertension.

17. Unwilling to participate in the study.

\section{Interventions}

Study participants were randomly assigned to receive 1) Metformin (500 mg to $2000 \mathrm{mg}$ in divided dosages as per glycaemic status. Patients also received supplemental insulin if required. 2) Insulin (Regular, neutral protamin hagedorn or both) was started at randomisation visit according to fasting and 2-hour postprandial plasma glucose values. Patients were frequently followed up as deemed suitable and monitored for glycaemic targets, any drug-related adverse events, hypoglycaemia, adherence to diet modifications along with foetal and maternal wellbeing. Dosages of metformin or insulin were titrated to achieve glycaemic targets, fasting plasma glucose $\leq 95 \mathrm{mg} / \mathrm{dL}$ and 2-hour postprandial plasma glucose $\leq 120 \mathrm{mg} / \mathrm{dL}$. Additional insulin supplement was given in metformin group if glycaemic targets were not achieved with lifestyle modification and maximum metformin dosage of 2 grams per day.

\section{Outcomes}

Primary endpoint was to test whether there was a difference between neonatal birth weights in the metformin and insulin groups. Secondary endpoints were gestational hypertension, maternal weight gain, preeclampsia, mode of delivery, gestational weeks at delivery, induction of delivery, shoulder dystocia, neonatal hyperbilirubinaemia, neonatal hypoglycaemia, Apgar score at 5 min after delivery, neonate transfer to intensive care unit, respiratory distress, preterm birth ( $<37 \mathrm{wk}$. of gestation) and satisfaction with the allotted treatment modality.

\section{Assessments}

All assessments were performed at the randomisation visit and at the study end visits if not stated otherwise.

\section{OGTT}

A sample for fasting plasma glucose was obtained. Glucose (75 $\mathrm{gm}$ ) in water was then given orally and plasma glucose was 
obtained at 60 and 120 minutes after glucose administration. The baseline investigation was performed at screening visit.

\section{Laboratory}

Glucose was measured by glucose oxidase method. $\mathrm{HbA}_{1 \mathrm{c}}$ was analysed by high performance liquid chromatography. Baseline biochemistry was performed at screening visit.

\section{Other Assessments}

A standard electronic scale was used to measure weight. Foetal ultrasound was carried out in Department of Radiology by experienced radiologist for all the subjects at baseline and thereafter as required. Subjects were evaluated for both maternal and fetal wellbeing by obstetrician at randomisation visit and thereafter as per obstetrician advice.

\section{Safety}

Adverse events were collected and recorded at all contacts with subjects after randomisation visit until the last contact, i.e. 7 days after delivery. A clinical examination was performed at the randomisation and followup visits. All biochemistry needed for assessment of eligibility was remeasured at delivery. Self-monitored blood glucose values and blood pressure were obtained at each visit.

\section{Randomisation}

A simple random sampling was performed creating a list including numbers 1-76 and intervention/active control treatment in a 1:1 ratio. An independent statistician created the list by computer software. Study subjects were allocated a randomisation number consecutively at the randomisation visit. They were then provided the corresponding medication. No blocking or stratification was performed.

\section{Blinding}

Study participants, study personnel, and investigators were not blinded to the allocated study intervention. All baseline data collection and its recording in the database were made before the randomisation code was broken.

\section{Statistics}

Descriptive statistical analysis has been carried out in the present study. Data is presented as means with SDs for continuous measurements as medians with IQRs or counts with percentages for categorical measurements. Significance is assessed at $5 \%$ level of significance. Normality of data tested by Shapiro-Wilk test. Unpaired t-test or Wilcoxon MannWhitney test has been used to find the significance of study parameters between two groups of patients according to the distribution of data. Chi-square/Fisher exact test has been used to find the significance of study parameters on categorical scale between two groups.

\section{RESULTS}

\section{Participant flow}

Participant flow is shown in flow chart (Figure 1). In study metformin arm $(\mathrm{n}=38), 3$ patients withdrew consent, 2 patients lost to follow up, 1 patient violated protocol, and one patient discontinued metformin and continued on insulin treatment to maintain normoglycaemia because of gastrointestinal side effects. In the insulin group ( $n=38), 2$ patients withdrew consent, 1 patient lost to follow up and 2 patients had violation of protocol. For the analyses, all subjects were referred to their original treatment groups.

\section{Baseline data}

The baseline maternal characteristics are seen in Table I. In this study, there were no differences in baseline maternal characteristics between the metformin and insulin groups.

\section{Outcomes}

As shown in Table II, there were no statistically significant differences in maternal data between metformin and insulin groups in this study except for postprandial plasma glucose and treatment satisfaction.

Neonatal data are presented in Table III. In this study, there were no statistically significant differences in birth weight (grams). There were no other significant differences in terms of neonatal complications between the groups. In study, there was one stillbirth at gestational week 38 in the insulin group. The likely cause of which was an umbilical cord complication. Data of this pregnancy were included in the results of maternal and neonatal data until birth.

Need for additional insulin among patients on metformin In this study, $25 \%$ of the patients in the metformin group $(8 / 32)$ needed additional insulin to maintain adequate glucose control. Maternal baseline characteristics such as age, parity, OGTT at randomisation, and $\mathrm{HbA}_{1 \mathrm{c}}$ did not differ significantly in the metformin subgroups (Metformin only and metformin with additional insulin).

\begin{tabular}{|c|c|c|c|}
\hline $\begin{array}{c}\text { Maternal } \\
\text { Baseline } \\
\text { Characteristics }\end{array}$ & $\begin{array}{l}\text { Metformin } \\
(n=32)\end{array}$ & $\begin{array}{l}\text { Insulin } \\
(n=33)\end{array}$ & $\begin{array}{c}\text { p- } \\
\text { value }\end{array}$ \\
\hline Age (years) & $25.61 \pm 4.72$ & $26.3 \pm 3.84$ & 0.52 \\
\hline Gravida & $1.84 \pm 0.86$ & $1.73 \pm 0.76$ & 0.58 \\
\hline History of GDM & $4(12.5)$ & $7(21.21)$ & 0.51 \\
\hline $\begin{array}{l}\text { Obesity (BMI } \\
\geq 30)\end{array}$ & 7 (21.88) & $10(30.3)$ & 0.44 \\
\hline $\begin{array}{l}\text { OGTT 0h } \\
\text { (mg/dL) }\end{array}$ & $100.03 \pm 10.79$ & $102.67 \pm 9.61$ & 0.30 \\
\hline $\begin{array}{l}\text { OGTT 1h } \\
(\mathrm{mg} / \mathrm{dL})\end{array}$ & $215.22 \pm 15.34$ & $216.61 \pm 22.39$ & 0.77 \\
\hline $\begin{array}{l}\text { OGTT 2h } \\
\text { (mg/dL) }\end{array}$ & $182.69 \pm 17.33$ & $179.0 \pm 20.98$ & 0.44 \\
\hline $\begin{array}{c}\text { Gestational } \\
\text { weeks at } \\
\text { Randomisation }\end{array}$ & $27.77 \pm 2.49$ & $28.33 \pm 2.57$ & 0.38 \\
\hline $\mathrm{HbA} 1 \mathrm{c} \%$ & $5.87 \pm 0.33$ & $5.88 \pm 0.34$ & 0.96 \\
\hline $\begin{array}{c}\text { Dose of } \\
\text { metformin (mg) } \\
\text { or/and insulin } \\
\text { (IU) }\end{array}$ & $\begin{array}{c}500-2000 \\
\text { (median } \\
1500)\end{array}$ & $\begin{array}{c}\text { 4-42 (median } \\
14 \text { ) }\end{array}$ & \\
\hline Type of insulin & & $\begin{array}{l}\text { short-acting } \\
\text { only } 26 \% \\
(\mathrm{n}=9), \\
\text { intermediate- } \\
\text { acting only } \\
14 \%(\mathrm{n}=4), \\
\text { short- and } \\
\text { intermediate- } \\
\text { acting } 60 \% \\
(\mathrm{n}=20)\end{array}$ & \\
\hline \multicolumn{4}{|c|}{ ternal Baseline Characteristics } \\
\hline
\end{tabular}




\begin{tabular}{|c|c|c|c|}
\hline Maternal data & $\begin{array}{c}\text { Metformin } \\
(n=32)\end{array}$ & $\begin{array}{l}\text { Insulin } \\
(n=33)\end{array}$ & $\begin{array}{c}\text { p- } \\
\text { value }\end{array}$ \\
\hline $\begin{array}{c}\text { Total weight gain } \\
(\mathrm{kg})\end{array}$ & $10.89 \pm 1.62$ & $11.57 \pm 2.14$ & 0.67 \\
\hline $\begin{array}{c}\text { PIH \# or } \\
\text { preeclampsia }\end{array}$ & 0 & 0 & 0 \\
\hline Polyhydramnios & 0 & 0 & 0 \\
\hline $\begin{array}{c}\text { HbA1c \% at } 36 \\
\text { Gestational week }\end{array}$ & $5.68 \pm 0.24$ & $5.67 \pm 0.21$ & 0.83 \\
\hline $\begin{array}{l}\text { Fasting 0h } \\
\text { (mg/dL) }\end{array}$ & $85.41 \pm 5.96$ & $82.27 \pm 5.57$ & 0.32 \\
\hline $\begin{array}{c}\text { Post prandial } 2 \mathrm{~h} \\
(\mathrm{mg} / \mathrm{dL})\end{array}$ & $121.28 \pm 11.0$ & $113.06 \pm 11.71$ & 0.005 \\
\hline Hypoglycaemia & $1(3.1)$ & $3(9.09)$ & 0.57 \\
\hline $\begin{array}{c}\text { Gestational week } \\
\text { at Labour }\end{array}$ & $37.48 \pm 1.29$ & $37.64 \pm 1.6$ & 0.67 \\
\hline Labour induction & $12(37.5)$ & $8(24.24)$ & 0.29 \\
\hline Vaginal delivery & $8(25)$ & $10(30.3)$ & 0.64 \\
\hline $\begin{array}{l}\text { Caesarean } \\
\text { section }\end{array}$ & $24(75)$ & $23(69.7)$ & 0.64 \\
\hline $\begin{array}{l}\text { Treatment } \\
\text { Satisfaction }\end{array}$ & 23 (70.97) & $10(30.3)$ & 0.002 \\
\hline
\end{tabular}

\begin{tabular}{|c|c|c|c|}
\hline Neonatal Data & $\begin{array}{c}\text { Metformin } \\
(\mathrm{n}=32)\end{array}$ & $\begin{array}{l}\text { Insulin } \\
(n=33)\end{array}$ & $\begin{array}{c}\text { p- } \\
\text { value }\end{array}$ \\
\hline Birth weight (grams) & $2840 \pm 320$ & $2850 \pm 570$ & 0.93 \\
\hline Apgar Score at $5 \mathrm{~min}$ & $8.71 \pm 0.78$ & $8.88 \pm 0.70$ & 0.36 \\
\hline Hypoglycaemia & $2(6.25)$ & $4(12.12)$ & 0.41 \\
\hline Hyperbilirubinaemia & $3(9.38)$ & $2(6.06)$ & 0.62 \\
\hline $\begin{array}{l}\text { Respiratory Distress } \\
\text { Syndrome (RDS) }\end{array}$ & $1(3.13)$ & $2(6.06)$ & 0.57 \\
\hline Prematurity & $7(22.58)$ & $10(30.3)$ & 0.57 \\
\hline Neonates to NICU & $3(9.38)$ & $5(15.15)$ & 0.47 \\
\hline Foetal Anomaly & $0(0)$ & $0(0)$ & 0 \\
\hline Shoulder dystocia & $0(0)$ & $1(3.03)$ & 0.32 \\
\hline Macrosomia $(\geq 4 \mathrm{Kg})$ & $0(0)$ & $1(3.03)$ & 0.32 \\
\hline Stillbirth & $0(0)$ & $1(3.03)$ & 0.32 \\
\hline
\end{tabular}

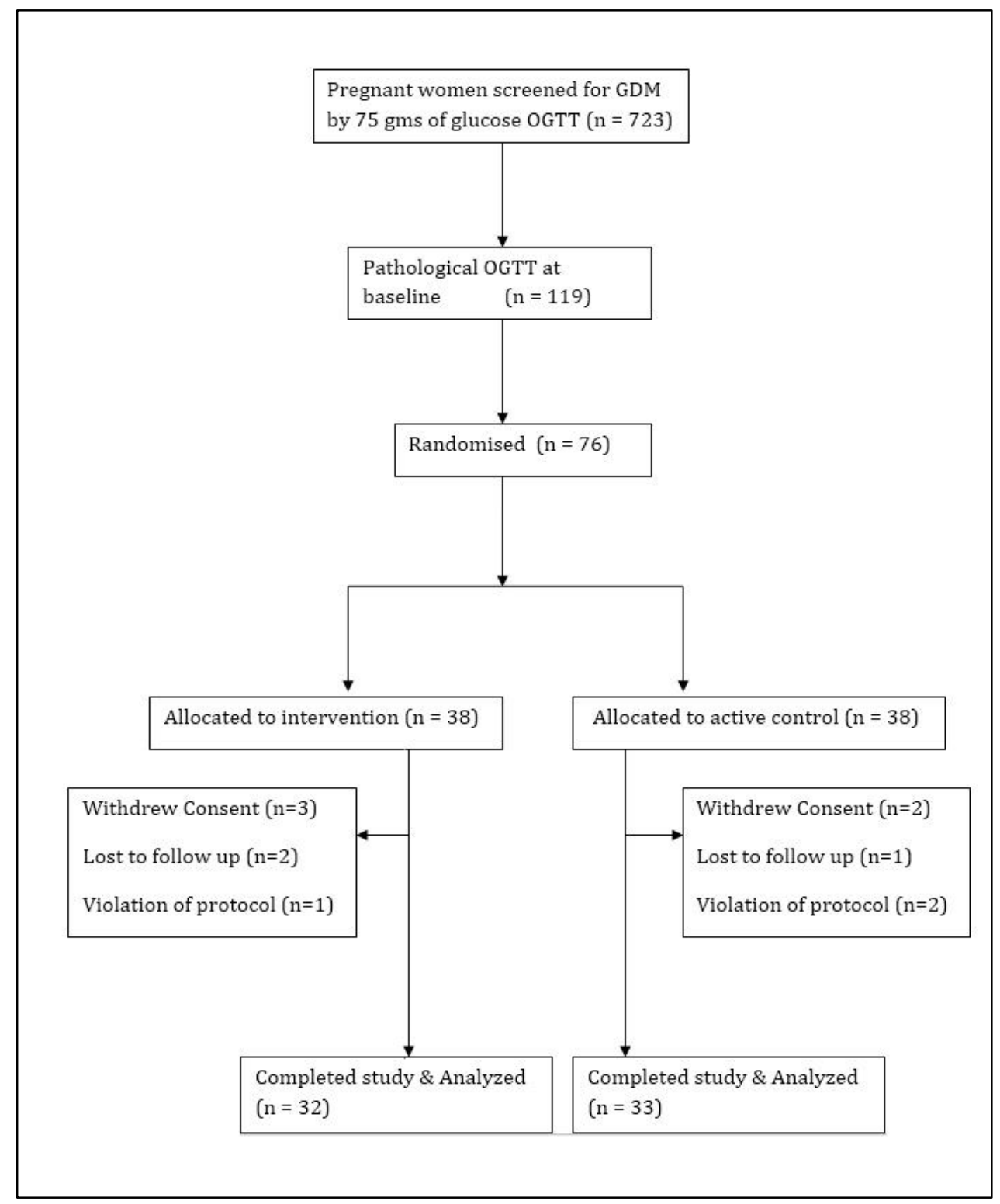

Fig. 1: Flow Chart 


\section{DISCUSSION}

Using medication during pregnancy requires consideration of the risks and benefits for the mother as well as for the unborn child. Possible long-term consequences that could affect the neonate and child must be evaluated. The medication must be essential, beneficial, and cannot be harmful. If there is a welldocumented pharmacological treatment for a given condition during pregnancy, an alternative drug must be documented sufficiently effective and safe before it can be considered for use during pregnancy. The use of metformin in gestational diabetes needs to fulfil these criteria. Thus, metformin must be confirmed to be safe for the mother and child and it must be effective in comparison to insulin.

In this study, there were no significant differences in mean birth weight and the other data describing the condition of the newborn between the insulin and metformin groups. The mean birth weight (2840 g) and the occurrence of neonatal hypoglycaemia (6.5\%) in the metformin group were much less compared with the results of Rowan et al(31) (3372 g and 15\%, respectively).

Metformin did not increase the maternal risks of blood pressure problems, assisted vaginal delivery or caesarean sections, since there were no differences in maternal data between the metformin and insulin groups. Comparison of the results of study with those from previous randomised trials sets limitations; because cut off values used for medical treatment, target glucose values during medication and population ethnicity between the studies vary. Ijas et al(32) reported more assisted vaginal deliveries and intra-labour caesarean sections for prolonged labour in the metformin group than the insulin group. In other randomised trials as also in present study, there were no differences in the mode of delivery.(31,33-35) Thus, metformin does not seem to increase delivery complications.

Since metformin does cross the placenta, it is essential to know whether this is neutral, beneficial, or harmful to the foetus of mothers on metformin with GDM. The safety of metformin was evaluated in study. The present results indicate that there is no increased risk to the foetus or the offspring when metformin is compared to insulin in GDM patients.

In randomised trials, comparing metformin with insulin in the treatment of GDM, less neonatal hypoglycaemia,(31,35) and more preterm births(31) were reported in the metformin group compared to the insulin group, but the difference in the rate of preterm births was not associated with other neonatal complications. In present study, there was no significant difference in occurrences of neonatal hypoglycaemia and preterm births between metformin and insulin groups. In fact, there were more preterm births in the insulin group than in the metformin group in the study of Mesdaghinia et al.(36) There was no difference in incidence of preterm births between the groups in other studies $(32,34,35)$ nor in this study. The risk of Respiratory Distress Syndrome (RDS) was low in this study and was not increased by the use of metformin according to previous studies.(31,33-35) In the study of Mesdaghinia et al(36) RDS was reported even more often in the insulin group than in the metformin group.

In this clinical study, the efficacy of metformin compared with insulin in GDM patients was evaluated. The target glucose values during medication were the fasting plasma glucose $<95$ $\mathrm{mg} / \mathrm{dL}$ and postprandial plasma glucose 2 hours $<120 \mathrm{mg} / \mathrm{dL}$.
Comparing glycaemic control between metformin and insulin groups is not fully relevant because the metformin group included patients needing additional insulin. Still in study, maternal glycaemic control was evaluated by $\mathrm{HbA1c}$ values at 36 gestational week, fasting, and postprandial plasma glucose. In this study, there was significant difference between the metformin and insulin groups for the postprandial plasma glucose levels at delivery. Postprandial plasma glucose was lower in insulin group in this study. Two randomised trials have reported better glucose control among metformin users than that insulin users based on postprandial glucose levels $(31,35)$ and on both fasting and postprandial values in an observational study of Rai et al.(37)

Some patients on metformin need additional insulin to meet glycaemic targets. In this study, 25\% of GDM patients in the metformin group needed additional insulin compared to 14-46\% in previous randomised trials comparing metformin with insulin in GDM patients.(31-35) In the study of Moore et al(33) none of the metformin-treated patients needed additional insulin. The varying results in different studies with respect to the need for additional insulin maybe explained first by different glucose inclusion criteria in the OGTT and second by different fasting and postprandial glucose treatment targets. In this study, the patients needing additional insulin did not differ significantly with respect to age, parity, their

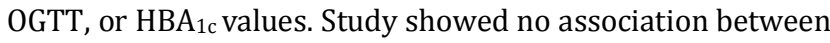
BMI, glucose values in OGTT, and a need for additional insulin contrary to the findings of Ijas et al.(32) The reason for this different result maybe chance, but the number of subjects in the study by Ijas et al(32) was greater than that in the present study.

Metformin often causes gastrointestinal side effects. However, in this study, only 1 patient $(3.2 \%)$ and in other randomised trials (31-35) only $0-6 \%$ of patients had discontinued metformin because of gastrointestinal symptoms. In the study of Rowan et al,(31) 77\% of metformintreated patients would choose metformin again.

There was one stillbirth in this study apparently due to an umbilical cord complication in the insulin group. There was one stillbirth in the metformin group in the study of Moore et al(33) and one stillbirth in the insulin group in the study of Rowan et al.(31) In other randomised trials, there have been no stillbirths reported.(32,34-36) When children of GDM patients exposed to metformin in utero have been compared to children exposed to insulin. It has been found that their weight and total body fat was similar, but metformin exposure was associated with more subcutaneous fat in the arm at age of 2 years. (38) This may, in fact, suggest a favourable fat distribution relating to use of metformin.

Current study shows that metformin is safe and effective in treatment of gestational diabetes mellitus. Acceptability of metformin is better than insulin as it is noninjectable and with negligible risk of hypoglycaemia. However, small percentage of patients may need additional insulin. Limitation of current study is small sample size. Future study involving large sample size may be useful in guiding the decision.

\section{ACKNOWLEDGMENTS}

The authors thank Dr. Pramit Ghosh (Assistant Professor, Department of Community Medicine Medical College, Kolkata) for invaluable work in this study. The authors also express 
gratitude to statistician Kingshuk Bhattacharyya for vital comments.

\section{REFERENCES}

1. Chen L, Magliano DJ, Zimmet PZ. The worldwide epidemiology of type 2 diabetes mellitus-present and future perspectives. Nat Rev Endocrinol 2012;8(4):228236.

2. American Diabetes Association. Diagnosis and classification of diabetes mellitus. Diabetes Care 2009; 32(Suppl 1):S62-S67.

3. Metzger BE, Coustan DR. Summary and recommendations of the fourth international workshop conference on gestational diabetes mellitus: the organising committee. Diabetes Care 1998;21(Suppl 2):B161-B167.

4. Ali S, Dornhorst A. Diabetes in pregnancy: health risks and management. Postgraduate Medical Journal 2011;87(1028):417-427.

5. Finucane MM, Stevens GA, Cowan MJ, et al. National, regional, and global trends in body mass index since 1980: systematic analysis of health examination surveys and epidemiological studies with 960 country-years and 9.1 million participants. Lancet 2011;377(9765):557-567.

6. Coustan DR, Lowe LP, Metzger BE, et al. The Hyperglycaemia and Adverse Pregnancy Outcome (HAPO) study: paving the way for new diagnostic criteria for gestational diabetes mellitus. Am J Obstet Gynaecol 2010;202(6):654.e1-654.e6.

7. Ferrara A. Increasing prevalence of gestational diabetes mellitus: a public health perspective. Diabetes Care 2007;30(Suppl 2):S141-S146.

8. Dabelea D, Snell-Bergeon JK, Hartsfield CL, et al. Increasing prevalence of Gestational Diabetes Mellitus (GDM) overtime and by birth cohort: Kaiser Permanente of Colorado GDM screening program. Diabetes Care 2005;28:579-584.

9. Crowther CA, Hiller JE, Moss JR, et al. Effect of treatment of gestational diabetes mellitus on pregnancy outcomes. N Engl J Med 2005;352(24):2477-2486.

10. Landon MB, Spong CY, Thom E, et al. A multicenter, randomised trial of treatment for mild gestational diabetes. N Engl J Med 2009;361(14):1339-1348.

11. Horvath K, Koch K, Jeitler K, et al. Effects of treatment in women with gestational diabetes mellitus: systematic review and meta-analysis. BMJ 2010;340:c1395.

12. Magon N, Seshiah V. Gestational diabetes mellitus: noninsulin management. Indian J Endocrinol Metab 2011;15(4):284-293.

13. Lee-Parritz A. Contemporary management of gestational diabetes. Curr Opin Endocrinol Diabetes Obes 2011;18(6):395-400.

14. Kjos SL, Buchanan TA. Gestational diabetes mellitus. N Engl J Med 1999;341(23):1749-1756.

15. United Kingdom Prospective Diabetes Study Group (UKPDS). 13: relative efficacy of randomly allocated diet, sulphonylurea, insulin, or metformin in patients with newly diagnosed non-insulin-dependent diabetes followed for three years. BMJ 1995;310(6972):83-88.

16. Kirpichnikov D, McFarlane SI, Sowers JR. Metformin: an update. Ann Intern Med 2002;137(1):25-33.

17. Hundal RS, Inzucchi SE. Metformin: new understandings, new uses. Drugs 2003;63(18):1879-1894.
18. Elliott BD, Langer O, Schuessling BA. Human placental glucose uptake and transport are not altered by the oral antihyperglycaemic agent metformin. Am J Obstet Gynaecol 1997;176(3):527-530.

19. Elliott BD, Schenker S, Langer O, et al. Comparative placental transport of oral hypoglycaemic agents in humans: a model of human placental drug transfer. Am J Obstet Gynaecol 1994;171(3):653-660.

20. Charles B, Norris R, Xiao X, et al. Population pharmacokinetics of metformin in late pregnancy. Ther Drug Monit 2006;28(1):67-72.

21. Briggs G, Freeman RK, Yaffe SJ. Drugs in pregnancy and lactation. $7^{\text {th }}$ edn. Philadelphia, USA: Lippincott 2005:p. 1017-1020.

22. Coetzee EJ, Jackson WP. Metformin in management of pregnant insulin-independent diabetics. Diabetologia 1979;16(4):241-245.

23. Coetzee EJ, Jackson WP. Pregnancy in established noninsulin-dependent diabetics. S Afr Med J 1980;58(20):795802.

24. Coetzee EJ, Jackson WP. The management of non-insulindependent diabetes during pregnancy. Diabetes Res 1986;1(5):281-287.

25. Checa MA, Requena A, Salvador C, et al. Insulin-sensitising agents: use in pregnancy and as therapy in polycystic ovary syndrome. Hum Reprod Update 2005;11(4):375-390.

26. Harborne L, Fleming R, Lyall $H$, et al. Descriptive review of the evidence for the use of metformin in polycystic ovary syndrome. Lancet 2003;361(9372):1894-1901.

27. Lord JM, Flight IH, Norman RJ. Metformin in polycystic ovary syndrome: systematic review and meta-analysis. BMJ 2003;327(7421):951-953.

28. Glueck CJ, Wang P, Kobayashi S, et al. Metformin therapy throughout pregnancy reduces the development of gestational diabetes in women with polycystic ovary syndrome. Fertil Steril 2002;77(3):520-525.

29. Jakubowicz DJ, Iuorno MJ, Jacubowicz S, et al. Effects of metformin on early pregnancy loss in the polycystic ovary syndrome. J Clin Endocrinol Metab 2002;87(2):524-529.

30. Glueck CJ, Bornovali S, Pranikoff J, et al. Metformin, preeclampsia, and pregnancy outcomes in women with polycystic ovary syndrome. Diabet Med 2004;21(8):829836.

31. Rowan JA, Hague WM, Gao W, et al. Metformin versus insulin for the treatment of gestational diabetes. $\mathrm{N} \mathrm{Engl} \mathrm{J}$ Med 2008;358:2003-2015.

32. Ijas H, Vaarasmaki M, Morin-Papunen L, et al. Metformin should be considered in the treatment of gestational diabetes: a prospective randomised study. BJOG 2011;118(7):880-885.

33. Moore LE, Briery CM, Clokey D, et al. Metformin and insulin in the management of gestational diabetes mellitus: preliminary results of a comparison. J Reprod Med 2007;52(11):1011-1015.

34. Niromanesh S, Alavi A, Sharbaf F, et al. Metformin compared with insulin in the management of gestational diabetes mellitus: a randomised clinical trial. Diabetes Res Clin Pract 2012;98(3):422-429.

35. Spaulonci CP, Bernardes LS, Trindade TC, et al. Randomised trial of metformin vs. insulin in the management of gestational diabetes. Am J Obst Gynaecol 2013;209(1):34.e1-e7. 
36. Mesdaghinia E, Samimi M, Homaei Z, et al. Comparison of newborn outcomes in women with gestational diabetes mellitus treated with metformin of insulin: a randomised blinded trial. Int J Prev Med 2013;4(3):327-333.

37. Rai L, Meenakshi D, Kamath A. Metformin-a convenient alternative to insulin for Indian women with diabetes in pregnancy. Indian J Med Sci 2009;63(11):491-497.
38. Rowan JA, Rush EC, Obolonkin V, et al. Metformin in gestational diabetes: the offspring followup (MiG TOFU): body composition at 2 years of age. Diabetes Care 2011;34(10):2279-2284. 